\title{
O PROCESSO HERMENÊUTICO DA INTERPRETAÇÃO: UMA ANÁLISE CRÍTICA DAS CONCEPÇÕES DE KARL LARENZ E HANS KELSEN SOBRE A BUSCA DO SENTIDO DA NORMA JURÍDICA
}

\section{THE PROCESS HERMENEUTIC INTERPRETATION: A CRITICAL ANALYSIS OF KARL LARENZ CONCEPTS AND HANS KELSEN ON THE DIRECTION OF LEGAL STANDARD SEARCH}

\section{Tarsis Barreto Oliveira ${ }^{1}$}

Resumo: O presente trabalho tem como objetivo abordar as concepções de Karl Larenz e Hans Kelsen sobre o processo hermenêutico da interpretação, como forma de revelação, por parte do intérprete, do sentido da norma jurídica. Nesta perspectiva, aborda-se inicialmente o ato de interpretar e a influência da pré-compreensão no processo de interpretação do Direito. Em seguida, foca-se o elemento valoração e o papel da jurisprudência, bem como os métodos de interpretação do Direito. Como caracteres fundamentais da concepção de Larenz e Kelsen sobre a interpretação, aborda-se a desvinculação do intérprete de seu sentimento pessoal de justiça, no plano do desenvolvimento e aperfeiçoamento do Direito. Por fim, são tecidas algumas críticas às concepções de Larnez e Kelsen, apontadas como falhas no pensamento engendrado pelos renomados autores.

Palavras-chave: Interpretação; Norma Jurídica; Intérprete; Jurisprudência; Valoração.

Abstract: This paper has as its goal to present Karl Larenz's and Hans Kelsen's conceptions about the hermeneutic process of interpretation, as a way of revealing, from the perspective of the interpreter, the sense of the juridical rule. In this way, we firstly analyse the act of interpretation and the influence of pre-comprehension in the process of Law interpretation. On the other hand, we focus on the element valuation and the role played by jurisprudence, as well as the methods of Law interpretation. As fundamental characters of Larenz's and Kelsen's conceptions regarding to interpretation, we analyse the interpreter's breaking from his personal feelings of justice, in the perspective of development and perfectionism of Law.

\footnotetext{
${ }^{1}$ Doutor pela Universidade Federal da Bahia. Professor da Universidade Federal de Tocantins, Araguaína, Tocantins, Brasil.
} 
At last, we make some critiques regarding to Larenz's and Kelsen's conceptions, considered flaws of these renewed authors.

Keywords: Interpretation; Juridical Rule; Interpreter; Jurisprudence; Valuation.

\section{INTRODUÇÃO}

A interpretação é um fenômeno imprescindível à compreensão, utilizando-se o intérprete de inúmeros mecanismos para a apreensão da realidade contida em uma norma. Com efeito, a distância existente entre a verdade contida em uma norma e a verdade abstraída pelo intérprete constitui-se um desafio a ser superado por todo aquele que interpreta, no esforço de apreensão, com a maior fidelidade possível, da pretensa vontade do legislador contida em um dispositivo.

Neste contexto, é recomendável uma atitude de abertura por parte do intérprete, a fim de evitar que o universo de sua pré-compreensão obstaculize a identificação do real sentido da norma, o que não impede a abstração de diferentes alcances interpretativos aplicáveis ao caso concreto. O desafio que se impõe ao intérprete de uma norma é o de evitar a apreensão da realidade numa perspectiva particular e intimamente contaminada pela influência valorativa e ideológica já presente em seu espírito, na medida em que esta possa distanciar-se do sentido originalmente construído pelo sujeito teleológico-estratégico que a esculpiu.

Examinam-se, nesta pesquisa, as concepções de Karl Larenz e Hans Kelsen sobre o processo interpretativo, na investigação dos mecanismos utilizados pelo intérprete para a apreensão do sentido contido na norma jurídica.

Inicialmente, investigar-se-á o real sentido do termo interpretar e a influência da précompreensão na interpretação do Direito. Em seguida, aborda-se o elemento valoração e o papel da jurisprudência na interpretação, bem como os métodos interpretativos dispostos no Direito. Como pontos-chave da compreensão de Larenz e Kelsen sobre a interpretação, focase a desvinculação do intérprete de seu sentimento pessoal de justiça, na perspectiva do desenvolvimento e aperfeiçoamento do Direito. Por fim, serão tecidas algumas críticas às concepções de Larenz e Kelsen, aqui vistas como falhas no pensamento dos renomados autores. 


\section{SOBRE O ATO DE INTERPRETAR:}

Propõe o presente capítulo uma breve análise doutrinária sobre o processo de interpretação, imprescindível ao aprofundamento das visões de Karl Larenz e Hans Kelsen ao longo do trabalho.

Entende-se por interpretação a busca do sentido e alcance de um objeto cognoscente por parte do intérprete, envolvendo, em seu contexto, um conjunto de mecanismos e técnicas tendentes à revelação do real sentido contido em uma norma e apreensível no universo de sua compreensão.

Foca este trabalho a interpretação de textos legais, ao mesmo tempo em que se reconhece um campo infinitamente mais amplo de um processo interpretativo, fazendo parte de toda realidade cognoscente do sujeito, enquanto ser vivo.

Com efeito, consoante explicita Macedo (1981, p. 92), a leitura do texto da lei é o ato inicial de qualquer trabalho interpretativo, constituindo-se no único elemento realmente indispensável ao trabalho interpretativo, na medida em que "não há como interpretar o vazio, a quanto se reduziria uma lei sem texto”.

Assim, qualquer captação ou assimilação de signos pode revelar a compreensão de um processo interpretativo, levando o intérprete à apreensão da realidade cognoscente e o seu posterior compartilhamento aos membros do grupo. Fala-se em interpretação não como uma transmissão de conhecimentos e verdades emanadas de um texto e apreendidas pelo intérprete, mas no resultado do inevitável choque entre as verdades nele contidas e o universo de sua pré-compreensão.

Realisticamente, não se pode conceber análises interpretativas que não levem em conta as concepções pessoais e valorativas do intérprete. Apesar de aparentemente indesejáveis sob o ponto de vista da captação do sentido de uma norma, as pré-concepções do intérprete entram inevitavelmente em choque com a verdade expressa nos dispositivos de um texto. Consideram-se, nesta análise, as disposições presentes nos textos legais, passíveis de interpretação pelos juristas e aplicadores da lei.

O choque que se apresenta no confronto entre a verdade prevista na norma e a sua apreensão pelo sujeito cognoscente (aqui, o intérprete), revela inevitáveis distorções entre o sentido original do texto e o sentido conferido por quem o examina.

A depender do nível de pré-compreensão do intérprete, aqui dizendo, do seu anterior nível de conhecimento do objeto tratado pelo texto, a interpretação tenderá a conduzilo de modo convergente ou divergente ao sentido originalmente imprimido pelo seu autor. 
Não obstante, parece razoável supor a existência de um nível de compreensão mínimo ao se examinar qualquer texto, por mais ininteligível que se apresente aos olhos do intérprete. Mesmo um texto em língua estrangeira, apresentado aos olhos de um intérprete sem qualquer conhecimento prévio do idioma, pode transmitir informações apreensíveis ao sujeito que o interpreta. Por exemplo, a própria constatação de que se trata de um texto em língua estrangeira revela o caráter de um exercício interpretativo.

São variados os níveis de apreensão cognoscente de um texto por parte de seu intérprete, este se utilizando, para a sua compreensão, de mecanismos linguísticos e semânticos. Com efeito, da análise interpretativa de um texto (aqui considerando todos os tipos de interpretação - gramatical, lógica, histórica, etc.), aufere-se sempre algum grau de compreensão da mensagem nele contida. As ferramentas que o intérprete dispõe são, na verdade, fruto de mecanismos racionais destinados à verificação da realidade contida no texto em exame.

Mas é preciso, aqui, uma atitude de abertura por parte do intérprete, a fim de que possa absorver o que o texto lhe apresenta. Gadamer (1997, p. 357-358) foca o choque promovido pela pré-compreensão do intérprete em confrontação com as informações contidas em um texto. Deste choque, nascem resistências, incompreensões ou compreensões, invariavelmente assimiladas, em maior ou menor medida, pelo espírito daquele que o confronta. Com efeito:

Em geral é preciso dizer que o que nos faz parar e perceber uma possível diferença do uso da linguagem é só a experiência do choque que um texto nos causa - seja porque ele não faz nenhum sentido, seja porque seu sentido não concorda com nossas expectativas. [...] Em princípio, quem quer compreender um texto deve estar disposto a deixar que este lhe diga alguma coisa. Por isso, uma consciência formada hermeneuticamente deve, desde o princípio, mostrar-se receptiva à alteridade do texto. Mas essa receptividade não pressupõe nem uma "neutralidade" com relação à coisa nem tampouco um anulamento de si mesma; implica antes uma destacada apropriação das opiniões prévias e preconceitos pessoais. O que importa é dar-se conta dos próprios pressupostos, a fim de que o próprio texto possa apresentar-se em sua alteridade, podendo assim confrontar sua verdade com as opiniões prévias pessoais.

Assim, para Gadamer, é preciso, para uma efetiva compreensão, uma atitude de abertura por parte do intérprete, mostrando-se receptivo à verdade proposta e lançada pelo autor, o que não subtende, entretanto, uma atitude passiva e neutra ao que lhe é apresentado.

Todorov (1978, p. 153), neste diapasão, destaca que o processo interpretativo sempre põe em evidência dois textos: o do autor e o do intérprete, sendo que o ato de interpretar implicaria em duas escolhas sucessivas. Nesta lógica, poder-se-ia impor ou não impor as 
coações sobre a associação dos dois textos e, após, ligá-los ao texto de partida, ao texto de chegada ou ao percurso por eles relacionado.

Heidegger, assim explicitado por Streck (2001, p. 196), entende a compreensão não como um modo de conhecer, mas como um modo de ser, visto que toda epistemologia é substituída pela ontologia da compreensão, de tal sorte que:

\begin{abstract}
A verdade não é uma questão de método. Será, assim, uma questão relativa à manifestação do ser, para um ser cuja existência consiste na compreensão do ser. Ser, verdade, vida e história são concebidos a partir da temporalidade absoluta, e não da temporalidade enquanto qualidade de um eu a-histórico e transcendental, próprios da metafísica. Na ontologia da compreensão, a vida é história, onde o próprio ser se desvela no horizonte da temporalidade. O próprio ser é tempo. Por isto, a vida, a existência concreta, emerge na compreensão do ser. Ela mergulha na temporalidade porque compreende o ser. A vida, é dizer, a existência, já é, desde sempre, porque o Dasein é pré-ontológico, compreensão do ser.
\end{abstract}

Não se vislumbra, portanto, uma apreensão integral da verdade originalmente pensada e construída pelo autor. É forçoso imaginar, na perspectiva do intérprete, um natural desvio no sentido e na valoração das proposições apresentadas, na medida em que as suas préconcepções colidem com os enunciados expostos pelo autor.

Para Larenz (1997, p. 282-284), a interpretação compreende um ato de mediação através do qual o intérprete compreende o sentido de um texto, tendo este se lhe deparado como problemático. Nesta lógica, o intérprete, de posse de diferentes significados possíveis para um termo ou para uma sequência de palavras, indaga-se sobre o seu correto significado, interrogando o contexto textual e o seu próprio conhecimento do objeto de que no texto se trata. Deve, então, o intérprete, examinar a situação que deu origem ao texto, bem como as circunstâncias hermeneuticamente relevantes, a fim de chegar a uma opção devidamente fundamentada entre diferentes possibilidades de interpretação, no sentido da busca de uma interpretação correta.

Assim, Larenz atribui a riqueza expressiva da linguagem à profusão de cambiantes presentes em um texto, chegando à conclusão de que todos os textos jurídicos são passíveis de interpretação, e não apenas os identificados como obscuros ou contraditórios.

Kelsen (2009, p. 387), neste diapasão, afirma a necessidade de fixação e interpretação das normas pelo órgão jurídico, consistindo esta interpretação em uma operação mental que acompanha o processo de aplicação do Direito no seu progredir de um escalão superior para um escalão inferior. O intérprete, aqui, deve buscar o conteúdo a ser atribuído à norma individual (de uma sentença individual ou de uma resolução administrativa), norma essa a deduzir da norma geral da lei na sua aplicação a um caso concreto. Kelsen destaca, ainda, uma interpretação da Constituição e uma interpretação dos tratados internacionais e das 
normas de Direito internacional consuetudinário, aplicáveis por um governo ou por um tribunal ou órgão administrativo, internacional ou nacional, sem olvidar, ainda, a interpretação de normas individuais, sentenças judiciais e ordens administrativas e negócios jurídicos.

E quando uma interpretação deve ser considerada pertinente? Como solução, Larenz (1997, p. 284-285) aponta a necessidade de identificação do escopo segundo o qual um texto deve ser interpretado. A opinião de um autor, para Larenz, interessa apenas na medida em que pode contribuir para a compreensão da coisa, constituindo-se na meta da interpretação, a exemplo dos testemunhos literários e das manifestações que expressam uma tomada de posição pessoal que o intérprete quisesse vivenciar e na descrição de experiências pessoais. A partir do escopo da interpretação, destacar-se-iam umas ou outras circunstâncias relevantes, traçando-se a linha diretriz segundo a qual devam ser interpretados os textos jurídicos, quer se tratem de leis, decisões judiciais ou negócios jurídicos.

Verifica-se que Kelsen e Larenz, neste ponto, chegam à mesma conclusão no sentido da necessidade em se buscar não apenas a compreensão das expressões linguísticas, mas o sentido normativo das normas. A interpretação é compreendida, assim, como um ato de mediação, pela qual o intérprete traz à compreensão o sentido de um texto que se lhe torna problemático, constituindo-se em um processo de duplo sentido, que transforma uma situação de fato em bruto em uma situação de fato aplicável, com a missão de evitar a contradição de normas.

Neste contexto, a interpretação é um processo dialético, através do qual faz-se falar o texto, sendo que o intérprete nunca se coloca de modo passivo, já que o texto só responde a quem o interroga corretamente.

Para Larenz (1997, p. 442), embora o juiz seja levado a interpretar um determinado termo ou uma determinada proposição jurídica para a solução de um caso concreto, deve interpretá-los não apenas para um caso concreto, mas de maneira a que a sua interpretação possa ser efetiva para todos os outros casos similares. Aí reside o caráter de universalidade na interpretação.

\section{A PRÉ-COMPREENSÃO NA INTERPRETAÇÃO}

De acordo com Gadamer (2002, p. 75), quem quiser compreender um texto deverá sempre realizar um projeto, sendo indissociável a influência da pré-compreensão no processo interpretativo, isso porque, ao interpretar, lemos o texto já com certas expectativas ou na perspectiva de um determinado sentido, sendo que a compreensão do texto consiste na 
elaboração desse projeto prévio, a sofrer uma constante revisão à medida que se aprofunda e amplia o sentido do texto.

Assim, para Gadamer (1997, p. 358), quem quer compreender um texto deve estar disposto a deixar que este lhe diga alguma coisa, mostrando-se receptivo à alteridade do texto, o que, não obstante, não implica uma neutralidade em relação à coisa ou um anulamento de si mesmo, mas, do contrário, uma destacada apropriação das opiniões prévias e preconceitos pessoais, a fim de que o texto possa apresentar-se em sua alteridade.

Larenz (1997, p. 286), igualmente a Gadamer, aborda a concepção de círculo hermenêutico, qualificando-o como uma especificidade do processo de compreender. Sobre este círculo hermenêutico, explicita:

Por tal, dizendo de modo simplificado, pretende expressar-se o seguinte: uma vez que o significado das palavras em cada caso só pode inferir-se da conexão de sentido do texto e este, por sua vez, em última análise, apenas do significado - que aqui seja pertinente - das palavras que o formam e da combinação de palavras, então terá o intérprete - e, em geral, todo aquele que queria compreender um texto coerente ou um discurso - de, em relação a cada palavra, tomar em perspectiva previamente o sentido da frase por ele esperado e o sentido do texto em seu conjunto; e a partir daí, sempre que surjam dúvidas, retroceder ao significado da palavra primeiramente aceite e, conforme o caso, retificar este ou a sua ulterior compreensão do texto, tanto quanto seja preciso, de modo a resultar uma concordância sem falhas.

Como se evidencia, a pré-compreensão e indissociável a todo processo de interpretação. Neste tocante, Boucault e Rodrigues (2002, p. 186) sugerem o fenômeno da construção da linguagem dos pré-conceitos, multiplicando, através da experiência compartilhada dos signos, o universo da compreensão humana, de tal sorte que:

\footnotetext{
Se a compreensão está determinada pelos "pré-conceitos" extraídos da experiência, e se a cada ato de conhecimento do mundo passa-se a contaminar o mundo com suas próprias impressões, está claro que o mundo está sendo construído pelo artifício dos "pré-conceitos". Esta construção, em verdade, consiste num processo de decodificação da linguagem do mundo, das linguagens da tradição em novas linguagens criadas a cada ato de compreensão do mundo.
}

A formação de uma conjectura de sentido é, para Larenz (1997, p. 288-290), factualmente difícil ou mesmo impossível, devido à presença da pré-compreensão, ainda que de início apenas vaga, por parte do intérprete. Esta pré-compreensão não se refere só à coisa Direito, à linguagem, à cadeia de tradição em que se inserem os textos jurídicos, às decisões e argumentos habituais, mas também a contextos sociais, situações de interesses e estruturas das relações da vida a que se referem as normas jurídicas.

Este é um ponto considerado fundamental na perspectiva de Larenz: a précompreensão não pode sobrepor-se à vinculação à lei e ao Direito, devendo haver uma 
vinculação do juiz às pautas do ordenamento jurídico, sendo que este ordenamento jurídico oferece, para uma generalidade de casos, sempre uma resposta plausível.

Neste sentido, Larenz (1997, p. 292-293) se coloca contra a arrogância judicial de certos juízes, ao afirmar que:

\begin{abstract}
o juiz que assim proceda considera-se a si próprio, graças à sua “pré-compreensão", como mais perspicaz que a lei e que os resultados por ela coenvolvidos mediante a interpretação jurisprudencial. O que não é compatível com a, se tomada a sério, "vinculação à lei e ao Direito", que a nossa organização judiciária impõe ao juiz, pois que esta exige que o juiz oriente a sua solução em primeiro lugar às pautas do ordenamento jurídico e isto do mesmo modo, e precisamente também, quando valora. [...] Para tal, tem de debruçar-se continuamente, mediante um processo de pré-compreensão, sobre o sentido intencionado, e que aqui é determinante, dessas pautas, processo que lhe requer a disponibilidade para questionar e retificar o seu entendimento prévio, face ao sentido que se lhe vai revelando. Isto só deixará naturalmente de acontecer se ele, ainda antes de entrar neste processo, deixar que o seu entendimento prévio se consolide desde logo em uma "conviç̧ão de justeza". Certamente que isto pressupõe que a eleição do método não seja pura e simplesmente deixada ao seu livre alvedrio e que o ordenamento jurídico, se inquirido de modo adequado, lhe fornecerá, pelo menos para a generalidade dos casos, uma resposta "plausível” - no sentido de um conteúdo mínimo de justiça da decisão.
\end{abstract}

A inevitabilidade da pré-compreensão no processo interpretativo decorre do fato de que ninguém está imune a pré-juízos. Para Larenz (1997, p. 293-295), a sua superação só pode se dar mediante um processo permanente de autoexame e a preocupação constante com a questão em si mesma, sendo esta, ademais, a primeira exigência que se impõe a um juiz como cientista do Direito. Há, forçosamente, a necessidade de se superar a distância temporal da norma, ou mais precisamente, a distância entre a necessária generalidade da norma e a singularidade de cada caso concreto.

A norma, nesse sentido, já está mais ou menos determinada no seu conteúdo, aguardando apenas a sua concretização no processo, sendo que a interpretação extraída da norma, com vistas à sua aplicação, não acrescenta nada à norma no decurso do processo. Para Larenz (1997, p. 296), o juiz pode abandonar uma interpretação se esta se revelar insustentável, tendo em vista o seu conteúdo significativo e as peculiaridades do caso presente. Esta é a razão pela qual deve o juiz buscar a concretização da norma, questionando a vinculatividade normativa do sentido a compreender, desempenhando os precedentes, neste mister, um papel fundamental.

Kelsen (2009, p. 14), por seu turno, em alusão ao aspecto temporal, salienta que a referência da norma ao espaço e ao tempo é o domínio da vigência espacial e temporal da norma, sendo este domínio limitado ou ilimitado, de tal sorte que:

A norma pode valer apenas para um determinado espaço e para um determinado tempo, fixados por ela mesma ou por uma outra norma superior; ou seja, regular 
apenas fatos que se desenrolam dentro de um determinado espaço e no decurso de um determinado período de tempo. Pode, porém, valer também - de harmonia com o seu sentido - em toda a parte e sempre, isto é, referir-se a determinados fatos em geral, onde quer que e quando quer que se possam verificar. É este o seu sentido quando ela não contém qualquer determinação espacial e temporal e nenhuma outra norma superior delimita o seu domínio espacial ou temporal. Neste caso, ela não vale a-espacial e intemporalmente, mas apenas sucede que não vigora para um espaço determinado e para um período de tempo determinado, isto é, os seus domínios de vigência espacial e temporal não são limitados.

Pensamento semelhante é manifestado por Larenz (1997, p. 448-449), para quem o escopo da interpretação é o sentido normativo do que agora é juridicamente relevante, ou seja, o sentido normativo da lei. Entretanto, para que seja considerado juridicamente relevante, deve atender a intenções de regulação e às ideias normativas concretas do legislador histórico, englobando-se todos os momentos mencionados, tanto objetivos quanto subjetivos.

Os precedentes cumprem, aqui, papel fundamental na apreensão do sentido da norma, repercutindo decisivamente no processo de construção do direito. Esta é a opinião de Larenz, para quem os precedentes acabam por apontar ou sugerir a direção e o sentido do Direito aplicável, buscando a uniformidade da jurisprudência e a segurança jurídica.

Neste tocante, Kelsen (2009, p. 278) entende que a decisão judicial pode ter um caráter de precedente quando a norma individual por ela estabelecida não é predeterminada, no tocante ao seu conteúdo, por uma norma geral criada por via legislativa ou consuetudinária, ou então quando essa determinação não é unívoca, engendrando diferentes possibilidades de interpretação. Nesta lógica, o tribunal que cria o precedente funciona como legislador, como o órgão a que a Constituição confere poder para legislar, sendo a decisão judicial de um caso concreto vinculante para a decisão de casos idênticos.

\section{A VALORAÇÃO NA INTERPRETAÇÃO DO DIREITO}

Para compreender uma norma, faz-se mister revelar o valor nela contido. Para Larenz (1997, p. 299), não se trata simplesmente de uma aplicação da norma, mas de realizar uma valoração que esteja de acordo com a norma ou o critério retor. Uma tal correspondência que não pode, portanto, significar equivalência, como na realização de uma subsunção; do contrário, precisa, para ser convincente, de múltiplas mediações.

Deste raciocínio, deduz-se que o legislador deve criar conceitos que se adéquem a situações de fato de modo tão preciso que o julgador não precise recorrer a pontos de vista valorativos, tornando, destarte, a aplicação do Direito segura. A preocupação exposta por Larenz é, de fato, que se possa constatar a situação de fato sem se recorrer a pontos de vista 
valorativos, sendo que, para que tal se proceda, deve o legislador conformar um conceito com uma situação de fato de modo extremamente preciso, elegendo, para isso, as notas características do conceito. Para Larenz (1997, p. 308-309), as notas características do conceito serão escolhidas por ele de tal modo que, ao aplicar o conceito, a questão relativa às notas características do conceito seja susceptível de subentrar no lugar da questão da valoração. A subsunção ao conceito é, pelo menos no caso ideal, um procedimento isento de valoração. Neste termos, aquele que aplica a lei ficará liberto do incômodo da ponderação valorativa, o que torna a aplicação do Direito segura.

Para Larenz (1997, p. 310-311), o pensamento orientado a valores justifica-se quando a lei recorre a uma pauta de valoração carecida de preenchimento para a delimitação de uma hipótese legal ou de uma consequência jurídica, a exemplo de pautas como a boa-fé, justa causa, prazo razoável, prudente arbítrio, dentre outras, de tal sorte que:

\footnotetext{
Estas pautas alcançam o seu preenchimento de conteúdo mediante a consciência jurídica geral dos membros da comunidade jurídica, que não só é cunhada pela tradição, mas que é compreendida como estando em permanente reconstituição. Os tribunais consideram-se de certo modo como "caixas de repercussão" dessa consciência jurídica geral e, neste sentido, orientam-se predominantemente pelos exemplos de decisões tidas como inquestionáveis ou corroboradas por uma larga jurisprudência.
}

O pensamento orientado a valores é imprescindível na Jurisprudência e não pode equiparar-se a valores pessoais. Lembra Larenz (1997, p. 408) que a questão da adequação de uma consequência jurídica (a uma situação de fato de determinada espécie) é uma questão de valoração, empreendida pelo julgador dentro do quadro previamente dado pela norma. A valoração, nesta perspectiva, é entendida como uma tomada de posição, fundamentável mediante considerações de ordem jurídica. Esta é, pois, a função do juiz: a concretização de uma pauta de valoração carecida de preenchimento. Kelsen (2009, p. 19), por seu turno, entende que valores constituídos neste processo são arbitrários, isso porque o fundamento dos juízos de valor é estabelecido pela vontade humana, e não por uma vontade supra-humana, razão pela qual ditos valores são considerados relativos, podendo ser bons ou maus.

\section{O PAPEL DA JURISPRUDÊNCIA NA INTERPRETAÇÃO.}

A jurisprudência tem, segundo Larenz (1997, p. 330), um tríplice papel, qual seja, o de tornar claros como problemas jurídicos os problemas que se apresentam (com todas as implicações resultantes), a elaboração de soluções que se ajustem ao Direito vigente, bem como a prestação de ajuda na formulação de hipóteses. Daí decorre a necessidade, verificada 
pelo citado autor, de contínuo exame da anterior interpretação da norma, a fim de corrigi-la e desenvolvê-la, isso em função da amplitude de variações da situação fática.

Larenz (1997, p. 338) afirma que a jurisprudência promove a consciência coletiva dos conteúdos de justiça, já que revela princípios jurídicos retores e os concretiza em contextos diversos, acabando por contribuir para o melhor conhecimento dos princípios de um Direito justo.

Kelsen (2009, p. 263), por seu turno, entende que o estabelecimento de uma norma individual pelo tribunal representa um estágio intermediário do processo, que começa com a elaboração da Constituição, chegando à decisão judicial e execução da sanção, partindo-se, nesta perspectiva, do geral para o abstrato, correspondendo, pois, a um processo de individualização ou concretização.

Larenz (1997, p. 349) foca a problema sob o ponto de vista da pretensão de validade, correspondendo esta, segundo ele, a uma exigência vinculante de comportamento (norma de conduta) ou uma pauta vinculante de julgamento (norma de decisão). Assim, várias proposições jurídicas poderão incidir sobre o caso concreto, cabendo ao intérprete aplicá-las de forma coerente com a vontade do legislador. As proposições jurídicas são, destarte, regras de conduta ou de decisão, expressas em forma de linguagem, devendo ser aplicadas ao caso concreto. Kelsen (2009, p. 264), por seu turno, salienta a necessidade de verificação pelo tribunal se existem in concreto os pressupostos de uma consequência do ilícito determinados in abstrato por uma norma geral, devendo o tribunal não somente responder à quaestio facti, como também à quaestio juris.

Larenz (1997, p. 376) pondera, entretanto, que eventualmente duas ou mais normas podem parecer incidir sob uma mesma hipótese fática, cabendo ao juiz, neste caso, verificar se uma exclui a outra ou se ambas são aplicáveis, isso se as suas previsões forem coincidentes. É por essa razão que se devem verificar, dentro das proposições jurídicas, as consideradas relevantes.

Assim, o julgador deve reduzir a situação de fato a enunciados, verificando as normas jurídicas aplicáveis ao caso concreto. Passa-se, dessa forma, da situação de fato em bruto a uma situação de fato acabada, de uma norma em bruto a uma norma concretizada. Deve-se, então, selecionar as proposições jurídicas pertinentes, verificando quais as normas aplicáveis no caso concreto.

Esta seleção das proposições jurídicas consideradas relevantes para a conformação da situação de fato ocorre, segundo Larenz (1997, p. 396), de modo a que o julgador, partindo da 
situação de fato em bruto, coloque à prova as normas potencialmente aplicáveis, afastando as que se revelarem inaplicáveis.

Assim, resta meridiano que o juízo de valor se liga à consequência da escolha, sendo que a valoração implica numa tomada de posição.

Lembra Larenz (1997, p. 414) o papel atribuído ao juiz de resolver os conflitos que chegam às suas mãos, incumbindo-lhe julgar de um ou de outro modo a situação de fato que lhe é submetida, aceitando, para isso, o inevitável risco de insegurança para a jurisprudência dos tribunais. Neste ponto, uma resolução seria plausível quando bons argumentos apontassem tanto no sentido da sua correção, como em sentido oposto.

Percebe-se, com evidência, que, para a conformação da situação de fato, examinam-se as normas jurídicas potencialmente aplicáveis e as pautas de apreciação nelas contidas.

A tarefa do juiz, para Larenz (1997, p. 429), consiste então em apreciar e conformar juridicamente as situações de fato, orientando-se pelas previsões das normas jurídicas potencialmente aplicáveis e pelas pautas de apreciação nelas contidas, bem como aos eventos reais constatáveis pelo juiz. A percepção da situação de fato pelo juiz, na visão de Larenz, é auferida por percepções alheias, que lhe chegam ao conhecimento. Não obstante, pode ele inspecionar determinados objetos pertinentes à situação de fato, a fim de auferir com mais nitidez a realidade.

A conduta regulada pelas normas, informa Kelsen (2009, p. 15), é uma conduta humana, distinguindo-se em seu contexto um elemento pessoal e um elemento material, bem como o modo por que ele se deve conduzir, elementos estes ligados entre si de forma inseparável ${ }^{2}$.

Cabe ao juiz, então, proceder a uma resposta final à questão de direito, dependendo esta, segundo Larenz (1997, p. 437), da tomada em consideração das numerosas particularidades da situação de fato, diferentes de caso para caso, revelando-se uma maior aproximação em relação ao juiz de primeiro grau, visto este ter uma maior proximidade da matéria mediante o exercício de seu poder inquisitório.

\section{OS MÉTODOS DE INTERPRETAÇÃO.}

\footnotetext{
${ }^{2}$ Para Kelsen, não é o indivíduo como tal que, visado por uma norma, lhe fica submetido, mas o é apenas e sempre uma determinada conduta do indivíduo, de tal sorte que o domínio pessoal de validade refere-se ao elemento pessoal da conduta fixada pela norma.
} 
No que se refere aos métodos de interpretação, Kelsen (1997, p. 449-450) entende que ela não pode ser deixada ao simples arbítrio do intérprete, devendo, do contrário, proceder de modo seguro e comprovável; daí a importância dos critérios de interpretação, desenvolvidos pela metodologia jurídica, a servirem de guia ao intérprete, como os critérios histórico, literal, o contexto significativo da lei e o critério teleológico-objetivo.

Dentre os critérios de interpretação, afigura-se com maior grau de importância a interpretação literal. Com efeito, para Kelsen, o sentido literal, extraído do uso linguístico geral, constitui o ponto de partida do intérprete, determinando o limite da interpretação, já que aquilo que está além do sentido possível não pode valer como conteúdo da lei.

Portanto, como pondera Kelsen (2009, p. 391-392), deve-se considerar uma multiplicidade de significações verbais de uma norma inscritas na moldura do Direito, possíveis no confronto de todas as outras normas da lei ou da ordem jurídica. Essa é a razão pela qual, para o citado autor, todos os métodos de interpretação conduzem sempre a apenas um resultado possível, mas nunca a um resultado que seja unicamente correto.

Nesta mesma linha de pensamento, há de se distinguir, segundo Larenz (1997, p. 464), de um lado a intenção reguladora, os fins e a sua hierarquia, bem como as opções fundamentais do legislador e, por outro, as ideias normativas concretas das pessoas que tomaram parte na redação do texto legislativo. Nesta lógica, só os fins, estatuições de valores e opções fundamentais determinados na intenção reguladora ou que dela decorrem podem ser designados como vontade do legislador, realizada mediante a lei, este, pois, o sentido a orientar a interpretação, garantindo-se o papel preponderante dos órgãos legislativos no processo global de criação e concretização do Direito.

A este respeito, a visão de Kelsen é marcada pela ideia de moldura. Em sua concepção, o direito a ser aplicado forma uma moldura onde se encontram várias possibilidades de aplicação, donde se depreende que toda solução que se encontre dentro dela se mostre possível de ser aplicada.

O resultado da interpretação jurídica constitui-se, a partir daí, a fixação da moldura que representa o direito a interpretar, sendo que a interpretação de uma lei não deve conduzir necessariamente a uma única solução como a única correta, mas possivelmente a várias soluções com igual valor, apesar de somente uma delas acabar se tornando Direito positivo no ato do aplicador do Direito. (KELSEN, 2009, p. 390-391).

Neste ato de aplicação, a interpretação cognoscitiva combina-se com um ato de vontade em que o órgão aplicador do Direito efetua a sua escolha dentre inúmeras possibilidades, produzindo ou uma norma de escalão inferior ou executando-se um ato de 
coerção estatuído na norma jurídica aplicada, o que acaba por diferenciar uma interpretação jurídica $^{3}$ feita por um órgão aplicador do Direito de qualquer outra interpretação. (KELSEN, 2009, p. 394)

A ideia de hierarquia é ponto nevrálgico na compreensão de Larenz sobre a interpretação das normas jurídicas. Neste aspecto, Larenz (1997, p. 480-481) afirma a necessidade de se buscar a interpretação conforme a Constituição, devendo-se, para isso, procurar o sentido literal possível e o contexto significativo da lei. Esta fundamentação, em função da vinculação constitucional à lei e ao Direito, deve fundamentar-se à luz de argumentos jurídicos, devendo o juiz lançar mão de métodos jurisprudenciais.

Kelsen (2009, p. 247), a este respeito, afirma:

\begin{abstract}
A norma que regula a produção é a norma superior, a norma produzida segundo as determinações daquela é a norma inferior. A ordem jurídica não é um sistema de normas jurídicas ordenadas no mesmo plano, situadas umas ao lado das outras, mas é uma construção escalonada de diferentes camadas ou níveis de normas jurídicas. A sua unidade é produto da conexão de dependência que resulta do fato de a validade de uma norma, que foi produzida de acordo com outra norma, se apoiar sobre essa outra norma, cuja produção, por sua vez, é determinada por outra; e assim por diante, até abicar finalmente na norma fundamental - pressuposta.
\end{abstract}

Qualifica Kelsen (2009, p. 388-389), de relação de determinação ou vinculação a relação entre um escalão superior e um escalão inferior, a exemplo da relação entre a Constituição e a lei ou a relação entre a lei e uma sentença judicial. Nesta lógica, a norma de escalão superior regula o ato através do qual é produzida a norma do escalão inferior ou o ato de execução, determinando não só o processo em que a norma inferior ou o ato de execução são postos, mas também o conteúdo da norma a estabelecer ou o ato de execução a realizar. Quanto a uma norma geral, o seu estabelecimento ou fixação ocorre em correspondência com a sua natureza, sob o pressuposto de que a norma individual resultante de sua aplicação continua o processo de determinação da seriação gradual das normas jurídicas.

\title{
7. O SENTIMENTO PESSOAL DE JUSTIÇA DO INTÉRPRETE
}

O juiz não pode julgar segundo o seu sentimento pessoal de justiça. A afirmação de Larenz se justifica na medida em que esta atitude pode vir a engendrar processos de manipulação da lei, indesejáveis ao Direito. Admite-se, na concepção de Larenz, que o juiz tenha uma opinião preliminar, mas ele deve, em qualquer caso, estar disposto a que esta

\footnotetext{
${ }^{3}$ Neste turno, promove Kelsen uma diferenciação entre a interpretação do Direito feita pela ciência jurídica (interpretação não autêntica) da interpretação realizada pelos órgãos jurídicos (interpretação autêntica).
} 
opinião preliminar seja confrontada com a lei, a fim de auferir o sentido visado pelo legislador, evitando-se, destarte, que o seu pensamento pessoal venha a sobrepor-se à lei. Assim é que:

\begin{abstract}
Para alguns juízes é óbvia a tentação a deixar de lado, devido a esta meta, o complicado e nem sempre satisfatório caminho relativo à interpretação e aplicação da lei, e retirar a sua resolução diretamente do seu "arbítrio" judicial, do seu sentimento de justiça aguçado pela sua atividade judicial, do seu próprio entendimento do que é aqui “justo" e "equitativo". A fundamentação da resolução assim obtida efetua-se posteriormente, sendo que aí é a meta, precisamente a resolução antecipada, que determina o percurso. Qualificamos anteriormente (cap. I, $3 b)$ este procedimento como não legítimo, pois que não toma a lei como bitola do achamento da resolução e comporta o perigo de manipulação da lei. (LARENZ, 1997, p. 492).
\end{abstract}

A necessidade de vinculação do intérprete à lei é, pois, caminho indissociável de processo interpretativo, não podendo o juiz dela se afastar na escolha da solução jurídica ao caso concreto, pouco importando o sentimento pessoal de justiça do intérprete, e sim o sentido visado pelo legislador.

A justiça do caso concreto é uma meta desejável da atividade judicial, mas não um critério de interpretação, já que só pode realizar-se nos estreitos limites das leis vigentes e dos princípios reconhecidos e no decurso de um desenvolvimento jurisprudencial admissível. Assim, o fato de o juiz estar subordinado não altera em nada a sua obrigação de decidir segundo a lei, e nos termos da Constituição, evitando, dessa forma, eventual tomada de decisão baseada em convicção de retidão pessoal, não acobertada pela lei. Nesta lógica, a não ser que a própria lei deixe ao juiz uma margem de apreciação e valoração pessoais, o juiz tem de ater-se à lei e ao Direito, de tal sorte que a aspiração a uma justiça do caso é um fator legítimo no processo de decisão judicial, conquanto que não induza o juiz a manipular a lei de acordo com as suas convicções. (LARENZ, 1997, p. 493-494).

Este pensamento fundamenta a justiça como um critério relativo. Com efeito, afirma Kelsen (2009, p. 76) que uma teoria dos valores relativista não significa que não haja qualquer valor ou que não haja qualquer justiça, mas sim que não há valores ou justiça absolutos, somente valores e justiça relativos, razão pela qual os valores que nós constituímos não podem apresentar-se com a pretensão de excluir a possibilidade de valores opostos. Kelsen chega então à conclusão de que, assim como da Constituição não podemos extrair as únicas leis corretas, tampouco podemos obter as únicas sentenças corretas.

Mas como superar, no processo interpretativo, o inevitável obstáculo das lacunas? Elas são reais no sistema jurídico ou meramente aparentes? Para Larenz, a faculdade de desenvolver o Direito cabe indiscutivelmente aos tribunais, sempre que a lei contenha 
lacunas, não correspondendo estas ao limite do possível e admissível desenvolvimento do Direito em absoluto, mas antes a um limite de um desenvolvimento do Direito imanente à lei, e vinculado à intenção reguladora, ao plano e à teologia imanente à lei. Nesta ordem, na maioria dos casos em que falamos de uma lacuna da lei revela-se incompleta uma determinada regulação em conjunto, por não conter nenhuma regra para uma questão que, segundo sua intenção reguladora, precisa de uma regulação. (LARENZ, 1997, p. 524-528).

Neste mister, faz Larenz uma diferenciação entre lacunas da lei e lacunas do Direito, sendo que a falta de um instituto não pode ser considerada uma lacuna do Direito quando esta falta se referir a uma decisão consciente do legislador. Essencialmente, para Larenz, a terminologia lacuna do direito não é acertada, não admitindo a existência de lacunas no direito, mas, tão somente, de lacunas na lei, sendo muitas aparentes lacunas o resultado de uma má interpretação da lei. (LARENZ, 1997, p. 537).

Kelsen (2009, p. 273), por seu turno, não admite a existência de lacunas, fundamentando-se as teorias que a legitimam na ignorância do fato de que, quando a ordem jurídica não estatui qualquer dever de um indivíduo de realizar determinada conduta, permite esta conduta. Assim, apesar de em muitos casos não ser possível a aplicação de uma norma jurídica singular, é perfeitamente possível a aplicação da ordem jurídica (esta, também, uma aplicação do Direito).

As lacunas, sejam elas patentes ou ocultas, devem ser integradas, podendo esta integração se dar por analogia ou com referência à natureza das coisas. Com relação às lacunas ocultas, dita integração se daria por redução teleológica, promovendo-se as diferenciações requeridas pela valoração. Não obstante, o preenchimento inicial de uma lacuna da lei por analogia ou por redução teleológica, apesar de ser ato de conhecimento criativo, não corresponde a um ato de estatuição do Direito, visto ser, na perspectiva do aplicador, um ato de conhecimento, e não um ato volitivo, sendo considerada válida porque aplicada por um tribunal. (LARENZ, 1997, p. 561-588).

\section{INTERPRETAÇÃO COMO DESENVOLVIMENTO DO DIREITO}

A compreensão da interpretação judicial como um desenvolvimento do Direito é trazida, com grande evidência, por Larenz, ao lembrar que uma nova interpretação será mantida no futuro pela jurisprudência dos tribunais, sendo observada no tráfego jurídico. Assim, toda concretização da jurisprudência dos tribunais de uma pauta carecida de 
preenchimento implica num desenvolvimento do Direito, ao eliminar incertezas anteriormente existentes.

Para Larenz (1997, p. 569), não pode haver dúvida sobre a legitimidade de correções da lei feitas pelos tribunais, na medida em que, sem as correções, o fim da lei não seria atingido numa parte de casos, não se podendo evitar uma grave contradição de valoração ou uma clara injustiça.

Esta atividade criadora do Direito também é lembrada por Kelsen (2009, p. 260), para quem a atividade criadora do Direito funda-se exclusivamente na norma quer determina esta função. Nessa lógica, a proposição que afirma que uma norma pertence a uma ordem jurídica porque foi criada por um órgão da respectiva comunidade jurídica nada mais diz que a afirmação segundo a qual uma norma pertence a uma ordem jurídica porque foi criada de conformidade com a determinação de uma norma desta ordem jurídica e, em última linha, de conformidade com a determinação da norma fundamental desta ordem jurídica.

Note-se que, para Larenz (1997, p. 588), o desenvolvimento do Direito opera extra legem (à margem da regulação legal), mas intra jus, devendo obedecer aos princípios gerais da ordem jurídica e à ordem de valores estabelecida na Constituição, diferentemente da concepção kelseniana, em que a criação e aplicação do Direito devem ser distinguidas da observância do Direito:

Observância do Direito é a conduta a que corresponde, como conduta oposta, aquela a que é ligado o ato coercitivo da sanção. É antes de tudo a conduta que evita a sanção, o cumprimento do dever jurídico constituído através da sanção. Criação do direito, aplicação do Direito e observância do Direito são funções jurídicas no sentido mais amplo. Também o uso de uma permissão positiva pode ser designado como observância do Direito. Porém, só a criação e aplicação do Direito são designadas como funções jurídicas num contexto estrito específico. (KELSEN, 2009, p. 263).

Não obstante a margem de livre apreciação do juiz, este atua, em inúmeros casos, na observância da natureza das coisas, esta entendida por Larenz como um conceito teleológicoobjetivo de interpretação, servindo para a ponderação de bens no caso concreto, sendo, ademais, de fundamental importância para a aplicação do princípio da Justiça (tratar os iguais de forma igual e os desiguais de forma desigual na medida da sua desigualdade). Larenz fala, pois, de um desenvolvimento do Direito superador da lei, de acordo com um princípio éticojurídico, toda vez que um caso, ou uma série de casos, não puder ser solucionado de um modo a que satisfaça a sensibilidade jurídica com os meios da interpretação da lei, bem como de um desenvolvimento do Direito imanente à lei. (LARENZ, 1997, p. 594-599). 
A missão do sistema jurídico é, então, tornar visível e mostrar a conexão de sentido inerente ao ordenamento jurídico como um todo coerente. Para Larenz, o papel que as teorias jurídicas exercem neste processo é o de tornar claras as conexões e proposições jurídicas, com base nas normas jurídicas vigentes. Neste ponto, o sistema externo apresenta falhas, isso porque é impossível prever todas as hipóteses fáticas, além do que, em certos casos, os dispositivos legais não possuem um grau de precisão exigível para uma definição conceitual, provocando um esvaziamento de sentido, motivo pelo qual faz-se uso, não raro, da construção dos tipos, isso quando o conceito geral abstrato e o sistema lógico não forem suficientes para revelar as conexões e proposições jurídicas. (LARENZ, 1997, p. 642-665).

Sobre este processo dinâmico de concretização do Direito, entende Kelsen (2009, p. 263) que o estabelecimento da norma individual pelo tribunal representa um estágio intermediário que começa com a elaboração da Constituição, indo até a decisão judicial e desta até a execução da sanção, partindo-se do geral para o individual.

\section{CRÍTICAS ÀS CONCEPÇÕES DE KARL LARENZ E HANS KELSEN SOBRE O FENÔMENO INTERPRETATIVO}

O pensamento de Karl Larenz e Hans Kelsen, seguramente dois dos mais renomados juristas do século XX, contribuiu de forma singular para o desenvolvimento da ciência do Direito, seja com a introdução de conceitos e termos inovadores, seja com o valioso olhar metodológico e científico lançado sobre o fenômeno interpretativo.

De um lado, Larenz (1997) explicita, com maestria, os conceitos de validade normativa e pretensão de validade da norma, analisa o papel crítico da jurisprudência na construção do Direito, limita a pré-compreensão do intérprete às pautas do ordenamento jurídico, reforça a vinculatividade, unidade e segurança expressa pelos precedentes, lançando mão das proposições jurídicas e dos tipos jurídicos, no âmbito da compreensão da norma como ato de mediação.

Por seu turno, Kelsen (2009), em sua perspectiva pura, normativista e formalista do Direito, foca o debate na legitimidade da norma, com obediência e vinculação à chamada norma fundamental (grundnorm), diferencia os conceitos de validade, vigência e eficácia, a interpretação autêntica e não-autêntica, causalidade e imputação, normas e proposições jurídicas, dentro da concepção do processo interpretativo acoplado a uma moldura jurídica.

Ditas concepções, inovadoras e revolucionárias, dotadas de profundidade e coerência, dão margem, entretanto, a justificadas críticas, aqui elencadas, sobretudo, no que se refere ao 
caráter irrealístico de certas premissas, bem como à inconveniência, para o Direito, da adoção de algumas perspectivas no processo interpretativo. No que se refere ao âmbito da interpretação (foco desta pesquisa), elas se revelam ainda mais evidentes.

Com o intuito de fazer revelar estas incongruências, passa-se, neste capítulo, à confrontação crítica do pensamento de Larenz e Kelsen com outros autores, fazendo emergir a inconsistência de algumas das afirmações dos referidos autores.

Olvidam Larenz e Kelsen que em todo processo de interpretação e escolha das normas jurídicas aplicáveis, entra em cena um elemento modificador de seu dimensionamento e valoração: a vontade do próprio intérprete. Aqui, fala-se em vontade-decisão, que, invariavelmente, colocará a efeito um amplo conjunto de variáveis, as quais se incluem os valores próprios do intérprete, bem como os interesses que possui na escolha da solução mais adequada ao caso concreto.

Isto se evidencia porque o processo interpretativo não está imune a juízos axiológicos por parte do intérprete. Aristóteles (2007, p. 140), a propósito, já alertava que "é melhor aquilo que está livre das paixões que aquilo na qual elas são inatas. Enquanto a lei é isenta de paixões, a alma humana vive sob o domínio destas”.

Tal pensamento também é referendado por Nino (1974, p. 20):

\begin{abstract}
De esto se deduce que el derecho deve ser descrito en términos puramente fácticos, es decir, basándose en características observables. Para otras posiciones iuspositivistas esta conclusión se impone aun sin tener en cuenta las argumentaciones anteriores, fundamentándose en la conveniencia de mantener metódicamente separados el derecho y la moral y en la dificultad para obtener un acuerdo axiológico. En base a esto el positivismo jurídico prescribirá al jurista que, si desea descobrir cientificamente el derecho, deberá dejar de lado toda estimación valorativa del sistema normativo. Su objeto deberá acotarlo teniendo en cuenta exclusivamente critérios basados en propriedades empíricas.
\end{abstract}

A este propósito, o grande mérito de Perelman (1996) em sua obra Tratado da Argumentação foi justamente o de fazer revelar o caráter não-científico dos argumentos proferidos no mundo jurídico, descortinando a superficialidade e inconsistência das formulações que pretendem justificar, respaldar e legitimar o Direito.

Esta nova visão dos fatos engendra questionamentos às concepções trazidas por Kelsen, em sua obra Teoria Pura do Direito, concepções estas voltadas ao estudo da norma desprovida de toda ideologia e valoração.

A pretensa vontade da lei perpassa critérios de ponderação e compatibilidade diante das pré-compreensões valorativas do intérprete, porque intrínsecas e enraizadas ao seu universo cognoscente. Entretanto, independentemente deste choque visceral de compreensões, influem no processo interpretativo fatores externos ao intérprete, caracterizados por 
concepções ideológicas e interesses diversos que modificam os mecanismos de valoração da norma, presentes e indissociáveis à sua compreensão.

Por fim, não se pode olvidar que as concepções de Karl Larenz e Hans Kelsen deixam de lado o necessário exame das formas de manipulação do discurso jurídico, engendrada por mecanismos de apreensão e exercício do poder na construção e imposição dos valores contidos nas normas jurídicas.

\section{CONCLUSÃO}

Hans Kelsen e Karl Larenz, grandes expoentes da ciência do Direito no séc. XX, contribuíram decisivamente para a compreensão do fenômeno interpretativo da norma jurídica.

Neste processo interpretativo ocorre um choque entre o universo da pré-compreensão do intérprete e o universo de informações contidas na norma jurídica, incumbindo-lhe apreender o real sentido e dimensão a ela atribuídos pelo legislador.

Com efeito, não se pode negar, no universo de compreensão do intérprete, a influência de suas pré-concepções na apreensão da realidade que se lhe apresenta. Todo processo interpretativo é, então, o resultado do choque entre a sua pré-compreensão e a verdade trazida pelo autor no confronto com a norma.

No que se refere à interpretação, a concepção de Kelsen baseia-se na construção conceitual de moldura jurídica, abrangendo uma multiplicidade de significações verbais para a norma jurídica, inexistindo, nesta visão, um único critério de interpretação, mas um conjunto de critérios capazes de extrair o real sentido da norma.

É indissociável à compreensão de Kelsen a ideia de hierarquia das normas, com a qual visualiza um sistema escalonado cujo ápice repousa na grundnorm (norma fundamental), verificando-se uma construção escalonada de diferentes níveis de norma jurídica, cuja unidade é fruto de uma relação de dependência de uma norma inferior à norma imediatamente superior.

Larenz, por seu turno, foca a sua compreensão do processo interpretativo a partir da necessária vinculação do intérprete à norma, não devendo dela se afastar na escolha da solução jurídica do caso concreto, pouco importando, nesta lógica, o seu sentimento pessoal de justiça.

A justiça é, pois, para Kelsen, um critério relativo, sendo irrelevante no ato da interpretação, já que basta ao juiz verificar o critério de validade da norma, a autorizar a sua 
escolha e aplicação no caso concreto. Para Larenz, entretanto, deve o juiz determinar o escopo segundo o qual um texto deve ser interpretado, buscando-se o sentido normativo dos dispositivos.

Para Larenz, a interpretação judicial promove um desenvolvimento do Direito, na medida em que as incertezas anteriormente existentes são eliminadas através da concretização da jurisprudência pelos tribunais, conferindo mais segurança e estabilidade nas relações jurídicas, o que é compartilhado por Kelsen, ao igualmente reconhecer uma atividade criadora do Direito atribuída à jurisprudência.

A concepção de Kelsen de pureza do Direito peca, com evidência, pelo seu formalismo e pela desvinculação que promove entre o Direito e as demais ciências sociais. Peca, ainda, por deixar de lado a discussão sobre a justiça de uma lei, bastando para ele, tão somente a verificação de sua validade para a fixação de sua legitimidade e aplicabilidade. A relação intrínseca do Direito com outras ciências e a incorporação, no ordenamento jurídico, de conceitos de natureza moral e social, bem como a ampliação da discussão sobre a legitimidade das normas acabam por eivar de inconsistência e inadequação as proposições trazidas pelo referido autor.

Larenz, por seu turno, ao afirmar que a interpretação não pode ser deixada ao arbítrio do intérprete, devendo ficar vinculada às pautas do ordenamento jurídico, reforça a cautela de que o juiz não julgue de acordo com as suas concepções pessoais, o que poderia levar a uma manipulação da lei. Assim, ainda que se admitisse a formação de uma opinião prévia por parte do magistrado, esta deveria ser confrontada com a lei, não podendo a ela se sobrepor.

Evidenciadas as diferenças entre os pensamentos de Larenz e Kelsen acerca do fenômeno da interpretação, pode-se inferir, como ponto de convergência na concepção de ambos os autores, que todo processo interpretativo faz revelar uma pretensa vontade contida em uma norma. Entretanto, o resultado deste processo hermenêutico não está alheio a influências externas e internas que atuam sobre o sujeito cognoscente, engendradas na subjetividade e no inexorável confronto axiológico indissociáveis ao ato de interpretar.

\section{REFERÊNCIAS}

ARISTÓTELES. Política. Trad. Pedro Constantin Tolens. São Paulo: Martin Claret, 2007.

BOUCAULT, Carlos Eduardo; RODRIGUEZ, José Rodrigo (Orgs). Hermenêutica plural: possibilidades filosóficas em contextos imperfeitos. São Paulo: Martins Fontes, 2002. 
GADAMER, Hans-Georg. Verdade e método I: traços fundamentais de uma hermenêutica filosófica. Trad. Flávio Paulo Meurer. Petrópolis: Vozes, 1997.

Verdade e método II: complementos e índice. Trad. Enio Paulo Giachini. Petrópolis: Vozes, 2002.

KELSEN, Hans. Teoria pura do direito. Trad. João Baptista Machado. 8. ed. São Paulo: WMF Martins Fontes, 2009.

LARENZ, Karl. Metodologia da ciência do direito. 3. ed. Trad. José Lamego. Lisboa: Calouste Gulbenkian, 1997.

MACEDO, Maury R. M. A lei e o arbítrio à luz da hermenêutica. Rio de Janeiro: Forense, 1981.

NINO, Carlos Santiago. Consideraciones sobre la dogmática jurídica: con referencia particular a la dogmática penal. México: UNAM, 1974.

PERELMAN, Chaim. Tratado da argumentação. Trad. Maria Emantina Galvão. São Paulo: Martins Fontes, 1996.

STRECK, Lênio Luiz. Hermenêutica jurídica em crise: uma exploração hermenêutica da construção do direito. Porto Alegre: Livraria do Advogado, 2001.

TODOROV, Tzvetan. Simbolismo e interpretação. São Paulo: Edições 70, 1978. 